\title{
Prospection aérienne en Touraine
}

$n^{\circ} 064420$

Jacques Dubois

\section{(2) OpenEdition}

Journals

Édition électronique

URL : http://journals.openedition.org/adlfi/14155

ISSN : 2114-0502

Éditeur

Ministère de la culture

Référence électronique

Jacques Dubois, "Prospection aérienne en Touraine », ADLFI. Archéologie de la France - Informations

[En ligne], Centre, mis en ligne le 09 mars 2015, consulté le 19 avril 2019. URL : http://

journals.openedition.org/adlfi/14155

Ce document a été généré automatiquement le 19 avril 2019.

(c) Ministère de la Culture et de la Communication, CNRS 


\title{
Prospection aérienne en Touraine
} $n^{\circ} 064420$

\author{
Jacques Dubois
}

1 Assez curieusement les années 1997, 1998 et 1999 se ressemblent au point de vue des conditions météorologiques, avec une sécheresse printanière importante, mais des mois de juin pluvieux : le déficit hydrique prometteur a été compensé par les précipitations qui ont suivi... Il a donc fallu commencer assez tôt les campagnes de vols pour espérer déceler surtout des enceintes fossoyées, les restes de substructions en dur étant ensuite peu visibles ou peu contrastés dans les blés mûrs.

2 Nous avons prospecté les zones habituellement riches en indices: la Champeigne tourangelle entre Cher et Indre et le Lochois, sans négliger la surveillance des fuseaux autoroutiers concernés par les projets de tracés Alençon-Tours et Tours-Vierzon.

3 C'est ainsi que, en plus des confirmations et compléments sur des sites connus, nous avons pu découvrir de nouveaux enclos à Reignac, Tauxigny, Manthelan, Bossée, Vou en 1997, et à Esvres, Cigogné et Saint-Antoine-du-Rocher en 1998.

4 Des indices inédits de constructions sont apparus sur Manthelan, Mouzay, Nouâtre, Theneuil et Rouziers, mais les découvertes les plus importantes ont été :

- en 1997, le grand ensemble gallo-romain de la Verrerie, à la sortie nord-ouest de Montrésor, supposé depuis longtemps et enfin apparu cette année-là dans les céréales.

- en 1998, l'établissement gallo-romain de Ligré, signalé au siècle dernier au confluent de la Veude et de la Chancelée, photographié pour la première fois. 
INDEX

Index géographique : Centre, Indre-et-Loire (37), Touraine

operation Prospection aérienne (PA)

Index chronologique : Gallo-romain

Mots-clés : enclos 